\title{
Out-of-Body Experience induced by hypnotic suggestion: phenomenology and perceptual characteristics
}

\author{
Patrizio Tressoldi ${ }^{11}$, Luciano Pederzoli ${ }^{2}$, \\ ${ }^{1}$ Science of Consciousness Research Group, Studium Patavinum, Università di Padova, \\ Italy; \\ ${ }^{2}$ EvanLab, Firenze, Italy
}

\begin{abstract}
The aim of this study is the investigation of the perceptual and cognitive characteristics of Out-of- Body Experiences (OBEs) induced by hypnotic suggestions.

Five participants selected for their experience with hypnotic experience were induced into an OBE and were requested to verbally describe six selected images, either one or two per session, that were located in two different rooms that were hundreds of kilometers from the place where they were in hypnosis.

Furthermore, their real-time phenomenological experience was investigated with respect to the minimal phenomenal selfhood (MPS) and the similarities with the characteristics of spatial and temporal perception reported in near death experiences (NDEs).
\end{abstract}

On average, the participants correctly identified $46.6 \%$ of the images, whereas two independent judges correctly identified $66.7 \%$ of them, compared to a probability of $25 \%$ expected due to chance.

The phenomenology of their out-of-body perceptual and cognitive experiences revealed a general commonality among all participants. All participants reported a phenomenological experience of a disembodied personal selfhood able to perceive simply by an act of will without the physical limitation of eyesight, to move in the environment instantaneously and exist in a sort of three-dimensional world with no awareness of time.

The validity of these first person verbal reports was discussed to determine whether they were due to real OBEs or to the participants' or the hypnotist's previous knowledge about OBE.

Keywords: hypnosis, Out of Body Experiences, phenomenology of consciousness, near-deathexperiences

${ }^{1}$ For correspondence: patrizio.tressoldi@ unipd.it 


\section{Introduction}

The Out-of-Body Experience (OBE) is a multi-faceted experience whose core characteristic is a first personal perspective in which the "self", "himself" or "centre of consciousness" is experienced as spatially separated from the body (Metzinger, 2005; Terhune, 2009; Carruthers, 2013). Given these characteristics, this particular state of consciousness attracts much interest spanning from the philosophy of mind to neurophysiology and to the study of consciousness in general (see Cardeña and Alvarado, 2014, for a review).

Usually, such an experience occurs as either an uncontrolled spontaneous event (Cardeña, 2005; Braithwaite et al., 2011), consequence of traumatic events such as epileptic discharges (Blanke and Castillo, 2007) and near-death-experiences (Parnia et al., 2014) induced by illusory own-body perceptions (Ehrsson, 2007) or electrical stimulation of specific brain areas (Blanke, Ortigue, Landis and Seeck, 2002).

In all these studies, the OBE was based on the participants' verbal reporting obtained by questionnaires or interviews.

When an OBE occurs unpredictably or induced by illusory own-body perceptions, it is not possible to study its phenomenology and characteristics extensively, apart from its neural correlates and how participants perceive their physical bodies (Blanke, 2012; Blanke and Arzy, 2005) and verify by a third-person perspective what they declare to perceive in this particular state of consciousness.

An OBE induced by hypnotic induction, seems a good mean to perform a phenomenological analysis because an interviewer can be with the experiencer at the time of the experience.

Hypnosis-induced OBEs (Nash, Lynn and Stanley, 1984; Tart, 1998; Tressoldi and Del Prete, 2007) are rare because experienced hypnotists as well as particular subjects who are willing to participate and trained into this special experience, are required.

However, since 1970, there has been an interest in the study of non-spontaneous, that is in self- or externally induced OBEs by some authors interested in extrasensory perception (ESP). Usually, the typical procedure was to ask participants to travel to a nearby location and to obtain information from preselected target material during an OBE and to report this information when they feel they have returned to their bodies. A review of this line of research is reported in Alvarado (1982) and Cardeña and Alvarado (2014).

For example, Palmer and Vassar (1974), attempted to induce OBEs by progressive muscular relaxation techniques and audio-visual stimulation and then instructed their participants to travel to another room and to try to see a target. However, the subjects who reported OBEs obtained scores demonstrating below chance results. Palmer (1978), in summarizing his experiments, did not find support for the hypothesis that subjects who report OBEs have ESP scores significantly above chance and significantly higher than the scores of subjects who did not report OBEs although an interaction was found between the type of induction and the direction of the ESP scoring.

A study in which OBE was induced using hypnosis is described in Tart (1998). Seven participants who were all in the upper $10 \%$ of the hypnotic susceptibility range, received a suggestion after they reached a very hypnotic state to move their consciousness to a distant locked laboratory and to carefully observe some special target materials. However, none of their reports matched the characteristics of the targets and no formal analysis was completed. 
Tressoldi and Del Prete (2007), aimed at comparing the differences between hypnosis with an OBE and ordinary (no OBE) hypnosis, with respect to the capacity to perceive distant pictures outside the sensory visual range. The first kind of suggestion emphasized the capacity to visualize a remote picture. The second kind of suggestion emphasized leaving the body and allowing the mind to go where the target was presented. The two instructions were applied in a within-subject design to control individual differences better. In this study, no differences were found between the two hypnotic inductions, and both obtained an overall accuracy of $3.7 \%$ above chance.

\section{Study aims}

This study is a conceptual replication of Tressoldi and Del Prete (2007). Here the accuracy of the participants in the image identification also was examined with respect to the physical orientation of the target image. In half of the sessions, the target was placed facing up and, in the other half, it was placed upside down.

Furthermore, the OBE has been examined from the perspective of the minimal phenomenal selfhood (MPS) as defined by Blanke and Metzinger (2009) whose central defining features are, (i) a globalized form of identification with the body as a whole (as opposed to ownership of body parts), (ii) spatio-temporal self-location and (iii) a first-person perspective (1PP).

Finally, we aimed at investigating the characteristics of perception and cognition during an OBE. To do so, we devised a semi-structured interview of eleven questions related to what was reported by people who experienced a Near Death Experience as described by Jourdan (2011). In particular we devised questions related to instantaneous moving and zooming, crossing through walls, the " $360^{\circ} "$ perception with an unlimited field of vision, the perception "from everywhere simultaneously", the perception of transparency and the peculiarities of time perception (i.e., a spatialized or frozen time), the ability to differentiate past, present and future.

Participants were asked simple questions about all of these features when their confirmed to be in an out of body state (see Procedure).

\section{Confirmatory hypothesis}

To achieve a statistical power of 0.80 and an estimated effect size (ES) of 0.4 with respect to the 0.25 chance level, all participants contributed to six trials each.

\section{Explorative Hypotheses:}

-During the OBE, the characteristics of the MPS will be a spatio-temporal self-location and a firstperson perspective (1PP) associated with a sense and a perception of disembodiment.

-During the OBE, the reported experiences will resemble those described in the NDE as reported by Jourdan (2011). 


\section{Materials and Methods}

\section{Ethical approval}

The study was approved by the Psychology Departments of Padova University ethical committee, prot. n. 2058 which comprised a signed consent form from the participants.

\section{Participants}

Five participants free from any clinical level of medical or psychiatric disease, that is compatible with the international clinical criteria defined in the main clinical guidelines, such as DSM V or ICD-10, were selected to take part in this study. Their inclusion was based on their personal experience with hypnosis ranging from 9 to 20 sessions and after a selection by the hypnotist who carried out multiple pilot sessions with each of them. Their demographical and general characteristics are reported in Table 1. The degree of hypnotic suggestibility was estimated using the Italian version of the Harvard Group Scale of Hypnotic Susceptibility, Form A (Pascalis, Russo and Marucci, 2000).

The previous OBE knowledge of each of the participants, was assessed by asking them how many books, papers or news articles they had read about this state of consciousness. We classified a knowledge based on no previous specific interest and readings about OBE as "low" and a knowledge based on specific interest and readings about this state of consciousness, as "high".

Author LP acted as hypnotist. He has more than twenty years' experience with experimental hypnosis, included OBE.

Table 1: Characteristics of the five participants.

\begin{tabular}{lccccccc}
\hline ID & SEX & Age & $\begin{array}{c}\text { Previous } \\
\text { OBE } \\
\text { experience }\end{array}$ & $\begin{array}{c}\text { Previous } \\
\text { OBE } \\
\text { knowledge }\end{array}$ & $\begin{array}{c}\text { Hypnosis } \\
\text { experience } \\
\text { (sessions) }\end{array}$ & $\begin{array}{c}\text { Hypnotic } \\
\text { Susceptibility } \\
\text { - total score* }\end{array}$ & $\begin{array}{c}\text { Sessions } \\
\text { in Lab }\end{array}$ \\
\hline S & M & 26 & NO & High & 10 & 8 & 4 \\
A & M & 30 & NO & High & 12 & 8 & 4 \\
Al & F & 32 & NO & High & 9 & 8 & 0 \\
F & F & 53 & YES & High & 20 & 9 & 1 \\
D & F & 26 & NO & Low & 11 & 9 & 1 \\
\hline
\end{tabular}

\section{Procedure}

Before starting the formal experiment and after signing the consent form, all the participants underwent one or two sessions per week to get used to the hypnotic procedure and OBE suggestions until the hypnotist decided they were ready to start the formal experiment. As described in the Supplementary Material, particular care was devoted to familiarizing each participant about how to reply verbally to the questions without losing his OBE state and how to feel comfortable in it.

On average, it took four specific OBE sessions for the participants to be ready for the experiment at a level suitable for them to be in hypnosis by phone in the case of difficulties in 
reaching the laboratory. Hypnosis by phone has a long history (Gravitz,1983), and it is particularly efficacious after the participants has been already in hypnosis by the same hypnotist in vivo.

The summary of the general induction procedure for hypnosis and the induction of the OBE is available in the Supplementary Materials.

In the formal sessions, the participants were requested to identify one image in each of a total of six sessions. We placed the images in two different rooms as long as it was possible to require the identification of two different images in a single session. In only two cases, the participants had sufficient time and concentration to identify two images in a single session reducing their overall sessions to four instead of six. In three cases, the image orientation was facing up and in the remaining three, it was upside down.

\section{OBE hypnotic induction procedure}

All sessions were carried out either in a light-proof and partially soundproof laboratory or at the participants' houses. In the case of sessions at the participants' houses, the participants were reached by the hypnotist by phone. The participants were lying on a reclined sofa and a digital voice recorder was placed close to the mouth or the phone to record all of their verbal statements. The formal experiment started with the following instructions:

"The aim of the study is to study the characteristics of the remote viewing of images in terms of an $O B E$ and how they are perceived in this condition. Once you have entered the OBE state, you will be asked some questions about how you feel. Later on, you will be asked to arrive at and enter the room where the image has been placed. Then, you will be asked to look toward where the image has been located and to describe it, trying to report any visual characteristics, your emotions and any other information ${ }^{2}$.

At the end, before ending the OBE state, you will be asked a series of questions about how you can perceive and "move" in this state of consciousness. Remember, you can stop the session at any time either by saying NO out loud or by gesturing with your right hand. "

If no further explanations were needed, the hypnotist then began the hypnotic induction. When the hypnotist was satisfied with the participant's hypnotic state, which correspond to the characteristics of very deep state, that is, loss of contact with the body, retarded psychological and physiological functioning, and lack of spontaneity as described by Erickson (1952), he continued with the OBE induction. When the participants were at home, the hypnotist, inferred the desired hypnotic state noticing the tone and rhythm of their voice. When the hypnotist was sure that the participant was in an OBE state, referring to his/her phenomenological accounts in response to the suggestions described in the Supplementary Material, he asked him/her the following questions, devised by the authors of this study, to investigate the MPS $^{3}$ :

a) Are you feeling your physical body?

b) Where can you see (perceive) your physical body?

c) What connection can you perceive with your physical body?

\footnotetext{
${ }^{2}$ All participants were offered the opportunity to describe the images by sketching, but everyone preferred the verbal option.

${ }^{3}$ During the sessions, participants were asked further questions related to other characteristics of their experience. Their answers are reported in Tressoldi et al.'s (2015) companion article.
} 
d) Can you perceive any boundaries as if you were in your physical body?

e) How would you describe this state of consciousness?

After these questions, the hypnotist gave suggestions regarding where to find the picture the participants were to describe to the hypnotist. The pictures were placed on a cabinet in two different rooms in Padova University's Department of Psychology building (more than $190 \mathrm{~km}$ from the laboratory or the participants' houses), one on the third floor and the second in the basement.

As the pictures were described, each participant was asked the following six questions to investigate their perceptual and cognitive functioning in that state of consciousness:

a) Did you experience motion towards the places suggested or did you find yourself there instantaneously?

b) Did you feel anything while you were moving through physical barriers?

c) Could you perceive everything simultaneously or did you feel a sort of exploration movement?

d) Could you perceive all aspects of an object simultaneously (view from above, below, etc.), or only one at a time?

e) Could you see anything hidden behind another object or could you see through it?

f) Could you experience the sense of time?

Furthermore, the following question was asked to check the reliability of participants' reports: "What day and time is it now?". We thought that if the participants gave descriptions based only on their knowledge or inferences, and not their real experience in this state of consciousness, they probably would report the right answer. As the results will show, their phenomenological experience of time was very different from that experienced in a normal state of consciousness.

Hereafter, the hypnotist gave the suggestions to return to the body and come out of the hypnosis. Before the participants left the session, they were asked to comment on and comments about their experience.

All the participants were asked the same questions in the same format. Sometimes it was necessary for the hypnotist to repeat the answer to verify if he had understood it correctly or to rephrase the answer to clarify its meaning.

Since we were interested in determining whether the participants were able to remember what they had experienced during the OBE when in a normal state of consciousness, at the end of the sessions, all participants were emailed the same six questions related to their perceptual and cognitive experience when in OBE, to answer in writing.

All original audio-recordings in Italian are available from Tressoldi (2013). Transcripts in English are currently underway.

\section{Answers analysis}

Two judges, PT and LP, independently analyzed qualitatively all five answers related to MPS and the six ones related to the NDE-like experiences, taking into account their contents following Krippendorff (2012) recommendations by listening to the original recordings. We pre- 
defined an overall agreement among participants when the same content was reported by at least 4 out 5 of them.

\section{Materials}

Six pictures were selected from the Geneva affective picture database (GAPED; DanGlauser and Scherer, 2011). Their inclusion criteria were a) high arousal values and b) all images related to human events. Their identification code and arousal score are presented in the Supplementary Material and available in Tressoldi, 2013.

\section{Identification of pictures}

To avoid any sensory leakage between the person who had chosen the target image and the participant, the author PT selected the six target images and randomized their order of presentation, the room where each one was placed and their orientation, either facing up or upside down, after which he informed the hypnotist that they were available without disclosing their identity.

When all five of the participants completed the identification of the two images, the hypnotist informed PT, who replaced the images with two new ones.

After completing the identification of two images, PT emailed each participant two sets of four images, the target image and three decoys (low arousal pictures) that were taken from other GAPED datasets, as well as the audio file of their descriptions, and requested to identify the targets. Once they had identified the target, the participants sent PT a copy of the selected images.

Furthermore, in order to ascertain if two independent judges could use the participants' descriptions to identify the target images, PT requested co-author LP and another independent judge affiliate with the EvanLab to identify them independently and blinded to the targets, using the same sets of images and listening to all five participants' recordings.

Each image was numbered from one to four. The location of the target within each set was randomized. All six sets of images are available from Tressoldi (2013).

All randomizations were made by using the online tools available at www.random.org

Feedbacks to the participants and the judges about their performance, was delivered at the end of the whole experiment to prevent unintentional communication of the targets' identity among them.

\section{Results}

\section{Data analysis}

In total, twenty-eight sessions were necessary to complete the study. Eighteen sessions were carried out by phone with the participants at home.

The percentages of correct identifications (hits) obtained by the participants and the two independent judges, are presented in Table 2. Overall agreement between the two judges was $90 \%$. Discrepancies were solved by re-listening the original recordings. 
Table 2: Raw scores and percentages of correct identification (hits out of 6 trials) of the participants and the two independent judges.

\begin{tabular}{lccc}
\hline Participant & $\begin{array}{c}\text { Hits face-up images } \\
(\mathrm{N}=3)\end{array}$ & $\begin{array}{c}\text { Hits face-down images } \\
(\mathrm{N}=3)\end{array}$ & Overall Hits (\%) \\
\hline $\mathrm{S}$ & 0 & 0 & 0 \\
\hline $\mathrm{A}$ & 1 & 1 & 33.3 \\
\hline $\mathrm{Al}$ & 1 & 3 & 66.7 \\
\hline $\mathrm{F}$ & 2 & 2 & 66.7 \\
\hline $\mathrm{D}$ & 2 & 2 & 66.7 \\
\hline Mean (\%) & $\mathbf{4 0}$ & $\mathbf{5 3 . 3}$ & $\mathbf{4 6 . 6}$ \\
\hline Judge 1 & 2 & 3 & 83.3 \\
\hline Judge 2 & 1 & 2 & 50 \\
\hline Mean (\%) & $\mathbf{4 2 . 8}$ & $\mathbf{6 1 . 9}$ & $\mathbf{5 2 . 4}$ \\
\hline
\end{tabular}

The overall $46.7 \%$ accuracy of the five participants and the $52.4 \%$ overall accuracy of participants plus the two independent judges, exceed the $25 \%$ expected by chance. We did not compare the two orientations (facing up or upside down) because of the low number of trials.

\section{Statistical method}

The Bayes factor (BF) compares the probability of the observed data under $\mathrm{H}_{1}$ versus $\mathrm{H}_{0}$, and hence quantifies the evidence that the data provide for and against the models under consideration. In our case, model $\mathrm{H}_{1}$, posits that the probability of hits is superior to model $\mathrm{H}_{0}$ positing that hits will approximate the chance expectation. When the BF exceeds 1.0 (i.e., the value indicating an identical probability of the two models) the evidence favors model $\mathrm{H}_{1}$ (the alternative model) over model $\mathrm{H}_{0}$ (the null model).

A convention proposed by some users of BF for interpreting the magnitude of the BF is that there is "substantial" evidence for $\mathrm{H}_{1}$ when the BF exceeds 3.0 and "extreme evidence" when the $\mathrm{BF}$ is greater than 100, and, equivalently, "substantial" evidence for $\mathrm{H}_{0}$ when the BF is less than 0.3 and "extreme evidence" when the BF is less than 0.01 (Wetzels, Matzke, Lee, Rouder, Iverson, \& Wagenmakers, 2011).

However, as for any measures of ES, these values must be interpreted within the research context where, for instance, even a small value may have an important relevance.

\section{Inferential statistics}

Binomial statistics with corresponding ES, 95\% Confidence Intervals (CI), and BF values calculated using the online calculator available here: http://pcl.missouri.edu/bf-binomial , are presented in Table 3 
Table 3: Binomial z-scores, with corresponding ES, 95\% CI, and $\mathrm{BF}_{\mathrm{H} 1 / \mathrm{H} 0}$ corresponding to the overall accuracy of all participants and participants plus the two judges.

\begin{tabular}{ccc}
\hline & Only participants & Participants plus two judges \\
\hline Binomial z & $2.53^{*}$ & $3.92^{\circ}$ \\
$E S\left(z / N_{n}\right)$ & $0.46[0.08,0.83]$ & $0.60[0.27,0.93]$ \\
$95 \% C I$ & & \\
$\mathrm{BF}_{\mathrm{H} 1 / \mathrm{H} 0}$ & 5.9 & 250 \\
\hline${ }^{*} p=0.006 ;{ }^{\circ} p=0.00004$ &
\end{tabular}

The obtained ES value is greater than the expected one of 0.37 . Furthermore, the BFs indicated that the alternative hypothesis $\left(\mathrm{H}_{1}>0.25\right)$ given the data, is approximately 6 to 250 times more probable than the null one $\left(\mathrm{H}_{0}=0.25\right)$.

\section{MPS and NDE-like experiences}

The summary of each participant's answer to each of the five questions related to the MPS is presented in Table 4.

Table 4: Participants' answers to the five questions related to the MPS.

\begin{tabular}{|c|c|c|c|c|c|}
\hline Participant & $\begin{array}{l}\text { Are you feeling } \\
\text { that you are in } \\
\text { your physical } \\
\text { body? }\end{array}$ & $\begin{array}{l}\text { Where can you } \\
\text { see (perceive) } \\
\text { your physical } \\
\text { body? }\end{array}$ & $\begin{array}{l}\text { What connection } \\
\text { can you perceive } \\
\text { with your } \\
\text { physical body? }\end{array}$ & $\begin{array}{l}\text { Can you } \\
\text { perceive any } \\
\text { boundaries as if } \\
\text { you were in your } \\
\text { physical body? }\end{array}$ & $\begin{array}{l}\text { How would you } \\
\text { describe this } \\
\text { state of } \\
\text { consciousness? }\end{array}$ \\
\hline $\mathrm{A}$ & No & $\begin{array}{l}\text { I cannot perceive } \\
\text { it }\end{array}$ & I see nothing & $\begin{array}{l}\text { I have an } \\
\text { external point of } \\
\text { view, but I } \\
\text { cannot see my } \\
\text { hands, feet or } \\
\text { body }\end{array}$ & $\begin{array}{l}\text { Beatitude; I feel } \\
\text { free }\end{array}$ \\
\hline $\mathrm{Al}$ & $\begin{array}{l}\text { No, there is no } \\
\text { contact }\end{array}$ & I feel suspended & $\begin{array}{l}\text { When I'm } \\
\text { speaking, I see a } \\
\text { sort of ethereal } \\
\text { link, but I cannot } \\
\text { see my body }\end{array}$ & $\begin{array}{l}\text { No, no } \\
\text { boundaries; }\end{array}$ & $\begin{array}{l}\text { Expanded; very } \\
\text { pleasant }\end{array}$ \\
\hline $\mathrm{D}$ & $\begin{array}{l}\text { I cannot perceive } \\
\text { it }\end{array}$ & $\begin{array}{l}\text { I feel it partially } \\
\text { seeing a sort of } \\
\text { non-material big } \\
\text { hands; It seems } \\
\text { to be elsewhere. }\end{array}$ & $\begin{array}{l}\text { I can see a sort } \\
\text { of silver cable } \\
\text { like a beam of } \\
\text { white light }\end{array}$ & $\begin{array}{l}\text { No, I have no } \\
\text { boundaries }\end{array}$ & $\begin{array}{l}\text { I feel very light; } \\
\text { very well; }\end{array}$ \\
\hline $\mathrm{F}$ & $\begin{array}{l}\text { I feel my body } \\
\text { only when I'm } \\
\text { speaking or } \\
\end{array}$ & $\begin{array}{l}\text { I cannot see it. I } \\
\text { feel it where I }\end{array}$ & $\begin{array}{l}\text { No connection; I } \\
\text { can see the silver } \\
\text { cable, but only if }\end{array}$ & $\begin{array}{l}\text { I feel totally } \\
\text { free; I do not } \\
\text { perceive }\end{array}$ & $\begin{array}{l}\text { I'm pure } \\
\text { awareness; It is a }\end{array}$ \\
\hline
\end{tabular}




\begin{tabular}{llllll}
\hline & $\begin{array}{l}\text { when I think } \\
\text { about it }\end{array}$ & $\begin{array}{l}\text { left it. I feel it as } \\
\text { stranger }\end{array}$ & $\begin{array}{l}\text { I pay attention to } \\
\text { it }\end{array}$ & $\begin{array}{l}\text { boundaries or } \\
\text { shapes }\end{array}$ & $\begin{array}{l}\text { state of } \\
\text { awareness }\end{array}$ \\
\hline $\mathrm{S}$ & $\begin{array}{l}\text { Partially, my } \\
\text { body seems like } \\
\text { a house. }\end{array}$ & $\begin{array}{l}\text { I feel it where it } \\
\text { is now }\end{array}$ & $\begin{array}{l}\text { I can feel it if I } \\
\text { want to. }\end{array}$ & $\begin{array}{l}\text { No, no } \\
\text { boundaries }\end{array}$ & Like a thought \\
& & & & \\
\hline
\end{tabular}

The summary of the participants' answers to each of the six questions related to the perceptual and cognitive characteristics of their OBE is presented in Table 5.

Table 5: Participants' answers to the six questions related to their perceptual and cognitive experience in their OBE

\begin{tabular}{|c|c|c|c|c|c|c|}
\hline Participant & $\begin{array}{c}\text { Did you } \\
\text { experience } \\
\text { motion towards } \\
\text { the places } \\
\text { suggested or did } \\
\text { you find } \\
\text { yourself there } \\
\text { instantaneously? }\end{array}$ & $\begin{array}{l}\text { Did you feel } \\
\text { anything } \\
\text { while you } \\
\text { were moving } \\
\text { through } \\
\text { physical } \\
\text { barriers? }\end{array}$ & $\begin{array}{l}\text { Could you } \\
\text { perceive } \\
\text { everything } \\
\text { simultaneously } \\
\text { or did feel like } \\
\text { a sort of } \\
\text { exploration } \\
\text { movement? }\end{array}$ & $\begin{array}{l}\text { Could you } \\
\text { perceive all } \\
\text { aspects of an } \\
\text { object } \\
\text { simultaneously } \\
\text { (view from } \\
\text { above, below, } \\
\text { etc.) or only } \\
\text { one at a time? }\end{array}$ & $\begin{array}{l}\text { Could you see } \\
\text { anything } \\
\text { hidden behind } \\
\text { another object } \\
\text { or could you } \\
\text { see through it? }\end{array}$ & $\begin{array}{l}\text { Could you } \\
\text { experience } \\
\text { the sense } \\
\text { of time? }\end{array}$ \\
\hline $\mathrm{A}$ & $\begin{array}{l}\text { I focused } \\
\text { immediately. }\end{array}$ & $\begin{array}{l}\text { No, I felt } \\
\text { nothing; } \\
\text { perhaps a } \\
\text { feeling of } \\
\text { warmth. }\end{array}$ & $\begin{array}{l}\text { Sometimes I } \\
\text { could perceive } \\
\text { all } \\
\text { simultaneously; } \\
\text { other times a } \\
\text { vague sense of } \\
\text { movement. }\end{array}$ & $\begin{array}{l}\text { I could } \\
\text { perceive it } \\
\text { simultaneously } \\
\text { from all points } \\
\text { of view. }\end{array}$ & $\begin{array}{l}\text { I knew it was } \\
\text { there; I could } \\
\text { see through the } \\
\text { object. }\end{array}$ & $\begin{array}{l}\text { No, I } \\
\text { didn't have } \\
\text { any sense } \\
\text { of time. }\end{array}$ \\
\hline $\mathrm{Al}$ & $\begin{array}{l}\text { I need not } \\
\text { move; first a } \\
\text { panoramic view, } \\
\text { followed by an } \\
\text { examination of } \\
\text { each thing at a } \\
\text { time. }\end{array}$ & $\begin{array}{l}\text { No, I felt } \\
\text { nothing. }\end{array}$ & $\begin{array}{l}\text { I could } \\
\text { immediately } \\
\text { perceive all the } \\
\text { things I was } \\
\text { interested in; } \\
\text { after that, I } \\
\text { could look at } \\
\text { them closely } \\
\text { without } \\
\text { moving. }\end{array}$ & $\begin{array}{l}\text { I could see it } \\
\text { from above, as } \\
\text { if from the } \\
\text { ceiling. }\end{array}$ & $\begin{array}{l}\text { I'm not sure, I } \\
\text { may have } \\
\text { moved. }\end{array}$ & $\begin{array}{l}\text { I felt no } \\
\text { sense of } \\
\text { time } \\
\text { travelling } \\
\text { to Padova; } \\
\text { I could } \\
\text { sense it } \\
\text { while } \\
\text { moving } \\
\text { around the } \\
\text { room and } \\
\text { while } \\
\text { watching } \\
\text { the objects } \\
\text { as if I were } \\
\text { in my } \\
\text { physical } \\
\text { body. }\end{array}$ \\
\hline $\mathrm{D}$ & $\begin{array}{l}\text { A bit like } \\
\text { zooming in } \\
\text { immediately. }\end{array}$ & $\begin{array}{l}\text { I felt as I was } \\
\text { moving } \\
\text { through } \\
\text { something } \\
\text { insubstantial; } \\
\text { I felt a barely }\end{array}$ & $\begin{array}{l}\text { I moved around } \\
\text { to explore } \\
\text { things; then I } \\
\text { could see } \\
\text { everything } \\
\text { simultaneously. }\end{array}$ & $\begin{array}{l}\text { I was watching } \\
\text { it from one } \\
\text { point of view at } \\
\text { a time, but I } \\
\text { perceived it as } \\
\text { a whole; I saw }\end{array}$ & $\begin{array}{l}\text { I moved to see } \\
\text { it; I was able to } \\
\text { see through it. }\end{array}$ & $\begin{array}{l}\text { I did not } \\
\text { experience } \\
\text { it while } \\
\text { moving } \\
\text { from one } \\
\text { place to } \\
\text { another; }\end{array}$ \\
\hline
\end{tabular}




\begin{tabular}{|c|c|c|c|c|c|c|}
\hline & & $\begin{array}{l}\text { perceptible } \\
\text { vibration. }\end{array}$ & & $\begin{array}{l}\text { all aspects of it } \\
\text { simultaneously. }\end{array}$ & & $\begin{array}{l}\text { while } \\
\text { watching } \\
\text { an object I } \\
\text { realized } \\
\text { time was } \\
\text { passing, } \\
\text { but I had } \\
\text { no sense of } \\
\text { time. }\end{array}$ \\
\hline $\mathrm{F}$ & $\begin{array}{l}\text { It felt like an } \\
\text { instant zooming } \\
\text { in. }\end{array}$ & $\begin{array}{l}\text { When } \\
\text { moving } \\
\text { through } \\
\text { quickly I felt } \\
\text { nothing; } \\
\text { when } \\
\text { moving } \\
\text { through } \\
\text { slowly, I felt } \\
\text { something } \\
\text { very faint } \\
\text { like getting } \\
\text { into water. }\end{array}$ & $\begin{array}{l}\text { I could see } \\
\text { everything } \\
\text { simultaneously. }\end{array}$ & $\begin{array}{l}\text { I could see it } \\
\text { any way I } \\
\text { wanted, } \\
\text { depending on } \\
\text { my level of } \\
\text { attention to it. }\end{array}$ & $\begin{array}{l}\text { I could see } \\
\text { everything } \\
\text { simultaneously; } \\
\text { I saw what I } \\
\text { needed to } \\
\text { know. }\end{array}$ & $\begin{array}{l}\text { Not at all, I } \\
\text { was aware } \\
\text { of the } \\
\text { succession } \\
\text { of events, } \\
\text { but not of } \\
\text { time. I } \\
\text { could sense } \\
\text { time if I } \\
\text { moved } \\
\text { slowly. }\end{array}$ \\
\hline $\mathrm{S}$ & $\begin{array}{l}\text { I moved a sort } \\
\text { of arm to touch } \\
\text { an object and I } \\
\text { could perceive } \\
\text { all. }\end{array}$ & $\begin{array}{l}\text { I didn't feel } \\
\text { anything; } \\
\text { sometimes, a } \\
\text { sense of } \\
\text { coolness. }\end{array}$ & $\begin{array}{l}\text { I filled the } \\
\text { environment } \\
\text { up, as if I were } \\
\text { like a fluid to } \\
\text { discover it; } \\
\text { after that I } \\
\text { shifted my } \\
\text { attention to one } \\
\text { object at a } \\
\text { time. }\end{array}$ & $\begin{array}{l}\text { If I focused on } \\
\text { it, I could see } \\
\text { everything } \\
\text { simultaneously; } \\
\text { otherwise, only } \\
\text { one side at a } \\
\text { time. }\end{array}$ & $\begin{array}{l}\text { When I knew } \\
\text { there was } \\
\text { something } \\
\text { there, I didn't } \\
\text { have to move, } \\
\text { otherwise I had } \\
\text { to look for it. }\end{array}$ & $\begin{array}{l}\text { None sense } \\
\text { of time } \\
\text { when I } \\
\text { went to } \\
\text { Padova; I } \\
\text { could sense } \\
\text { it while } \\
\text { moving } \\
\text { slowly } \\
\text { around a } \\
\text { room. }\end{array}$ \\
\hline
\end{tabular}

To ascertain whether these verbal reports represented a real description of true OBEs or were simply a reconstruction based on the participants previous knowledge about this phenomenon or to the hypnotist induction procedure, the same eleven questions were requested to a group of seven participants, five females and two males, chronological age range from 25 to 54 , who declared to have had at least one real spontaneous OBE and a group of nineteen participants, nine females and ten males, chronological age range from 25 to 63, declaring to have only read about OBEs. These two groups were contacted by email or phone among the friends of the authors and the persons affiliated with the EvanLab, the research center of some co-authors, to take part to a survey about OBEs. All participants were requested to fill in the questionnaire and send it back by email.

The percentages of responses to eleven questions of participants induced in OBE and controls participants with and without spontaneous OBE, is presented in Table 6. Highest percentages are presented in bold. 
Table 6: Percentages of participants induced in OBE with hypnotic suggestions, with spontaneous OBE and who only read about OBE who responded similarly to the questions.

\begin{tabular}{|c|c|c|c|c|}
\hline Questions & Response & $\begin{array}{c}\text { Participants } \\
\text { induced in OBE } \\
\qquad n=5\end{array}$ & $\begin{array}{c}\text { Controls with } \\
\text { spontaneous } \\
\text { OBE } \\
\text { experiences } \\
\mathrm{n}=7\end{array}$ & $\begin{array}{l}\text { Controls without } \\
\text { direct experience } \\
n=19\end{array}$ \\
\hline $\begin{array}{l}\text { Are you feeling that } \\
\text { you are in your } \\
\text { physical body? }\end{array}$ & No & 100 & 85 & 52 \\
\hline $\begin{array}{l}\text { Where can you see } \\
\text { (perceive) your } \\
\text { physical body? }\end{array}$ & Where it is & 20 & 85 & 52 \\
\hline $\begin{array}{l}\text { What connection } \\
\text { can you perceive } \\
\text { with your physical } \\
\text { body? }\end{array}$ & $\begin{array}{l}\text { I see a sort of } \\
\text { ethereal link }\end{array}$ & 60 & 28 & 15 \\
\hline $\begin{array}{l}\text { Can you perceive } \\
\text { any boundaries as if } \\
\text { you were in your } \\
\text { physical body? }\end{array}$ & No & 100 & 85 & 52 \\
\hline $\begin{array}{l}\text { How would you } \\
\text { describe this state of } \\
\text { consciousness? }\end{array}$ & Positive & 80 & 14 & 0 \\
\hline $\begin{array}{l}\text { Did you experience } \\
\text { motion towards the } \\
\text { places suggested or } \\
\text { did you find } \\
\text { yourself there } \\
\text { instantaneously? }\end{array}$ & $\begin{array}{l}\text { Like an instant } \\
\text { zooming in }\end{array}$ & 80 & 57 & 42 \\
\hline $\begin{array}{l}\text { Did you feel } \\
\text { anything while you } \\
\text { were moving } \\
\text { through physical } \\
\text { barriers? }\end{array}$ & $\begin{array}{l}\text { I didn't feel } \\
\text { anything }\end{array}$ & 100 & 71 & 52 \\
\hline $\begin{array}{l}\text { Could you perceive } \\
\text { everything } \\
\text { simultaneously or } \\
\text { did feel like a sort } \\
\text { of exploration } \\
\text { movement? }\end{array}$ & Simultaneously & 80 & 14 & 26 \\
\hline $\begin{array}{l}\text { Could you perceive } \\
\text { all aspects of an } \\
\text { object } \\
\text { simultaneously } \\
\text { (view from above, } \\
\text { below, etc.) or only } \\
\text { one at a time? }\end{array}$ & Simultaneously & 80 & 57 & 36 \\
\hline
\end{tabular}




\begin{tabular}{l|c|c|c|c}
\hline $\begin{array}{l}\text { Could you see } \\
\text { anything hidden } \\
\text { behind another } \\
\text { object or could you } \\
\text { see through it? }\end{array}$ & $\begin{array}{c}\text { I could see } \\
\text { through the } \\
\text { object }\end{array}$ & $\mathbf{8 0}$ & $\mathbf{8 5}$ & 26 \\
\hline $\begin{array}{l}\text { Could you } \\
\text { experience the sense } \\
\text { of time? }\end{array}$ & Not at all & $\mathbf{1 0 0}$ & $\mathbf{1 0 0}$ & 63 \\
\hline
\end{tabular}

Given the special characteristics of our samples, we preferred to compare these percentages only by their descriptive statistic because we think not correct to generalize them to a population.

A clear difference between the responses of the participants who were induced in OBE by hypnosis and those who declared only bibliographical knowledge is evident in all questions. On the contrary, this difference was reduced to only seven out eleven questions (considering almost equivalent the percentages 100 and 83) when the comparison is with the sample of participants declaring at least one real OBE.

It is interesting to note that for this comparison, the main differences emerge for the questions related to the experiences of "movement" in this special status of consciousness.

\section{Discussion}

\section{Confirmatory hypothesis}

\section{Participants' images identification}

Participants' overall accuracy of $47.6 \%$ with respect to the expected chance of $25 \%$, is higher than that observed by Tressoldi and Del Prete (2007). Plausible causes of the differences are a more selected sample and fewer identification tasks per session, one or two in this study versus two to four in Tressoldi and Del Prete (2007), that could have reduced the cognitive fatigue of participants. The overall accuracy of the two independent judges of $66.7 \%$, supports the hypothesis that participants' descriptions can be used to identify target images.

\section{Participants' MPS}

All participants, independently from their previous OBE experience and knowledge, reported an experience of disembodiment, with no sense of physical boundaries and a "Self" or "Iidentity" that was separated from their body. The connection with their physical body was described as either absent or having some form of connection sometimes described as a sort of silvered, bright white cable, when they spoke about or paid attention to their physical bodies. The emotional description of this state of consciousness was varied, but it was commonly characterized by a sense of well-being. It is important to remind that none of this information was suggested in the OBE induction. 
The hypothesis that during OBEs, the only characteristics of the MPS will be a spatiotemporal self-location and a first-person perspective (1PP) associated with a sense and a perception of disembodiment, seems to be completely supported.

Compared to Blanke and Metzinger's MPS description: "MPS is a phenomenal property, namely the conscious experience of being a self. It is the experience of being a distinct, holistic entity capable of global self-control and attention, possessing a body and a location in space and time", our participants reported an identical phenomenological experience, but without a physical body.

Furthermore, all reported having a first-person perspective (1PP) that, according to Blanke and Metzinger's description can be described as the strongest version of 1PP, which is characterized "not only as a self, but also as a self in the act of knowing which implies the possession of the concept of a subject of experience'.

To summarize, the reported phenomenology of our induced OBEs, seems compatible with a sort of Disembodied Phenomenal Selfhood (DPS), that retains all the characteristics of the strong version of the MPS except the possession of a physical body.

\section{Participants' OBE perceptual and cognitive characteristics}

With respect to whether the experiences reported during an OBE could resemble those reported in NDEs as discussed by Jourdan (2011), the answer is a definite yes.

The answers of all five participants to the eleven questions presented in Table 4 and 5, were quite similar in content regarding perception, movement around the environment and the sense of time, with some minor differences in the details they used to describe their experiences.

The acquisition of visual information is described as a purely perceptual act regulated only by the participant's intention or goal. The description of the act of perceiving as a "zooming in" that encompasses all points of view, is quite remarkable. From the participants' reports, it clearly emerges that, in this state of consciousness, "perception" is not dependent upon eyes. Even if it was quite expected, our participants described this difference with certain details which so far have not yet been documented.

Even the descriptions of moving around the environment and the sense of time offer some very interesting details. Travel across long distances seems to occur instantaneously. On the contrary, a vague sense of the sequence of events, associated with some sense of time, is described when a concentrated inspection of the environment is required. In general, it appears that they are living in a sort of world in which only the dimension of space, without that of time, is present.

Identical reports, with minor differences in the details, were described in the questionnaire that the participants were requested to fill in after the completion of all of the sessions, suggesting that in their normal state of consciousness, they retain accurate memories of their OBE experiences.

In summary, from all of the participants' phenomenological reports, it appears that in this state of consciousness they can act without the limitations that the physical body imposes on motion and perception especially with regard to vision. "Movement" and "perception" are mainly regulated by their intentions and goals. What they perceive depends upon what they want to know. This characteristic allows them to "move" instantaneously and to perceive things zooming toward them 
from all points of views. The participants only perceive a vague sense passing or a sequence of events when they search for details or move around to explore the environment. Time seems to be absent or similar to a sequence of video-clips, suggesting that they are living in a four-dimensional universe, very similar to that described as the "Block Universe" which represents space-time as a fixed whole in which past and future events already exist in the space-time continuum, in accordance with the special theory of relativity (Ellis, 2007; Petkov, 2006).

\section{Study limitations}

\section{Reliability of the OBE status of participants}

Where participants induced in a real OBE status of consciousness? Are the participants describing a real alternative state of consciousness that is different from our normal daily state, or are they describing what they expect, or think should happen during an OBE? The limits of firstperson verbal reports are well-known although they are essential to the investigation of personal phenomenology. Very probably, a convergence of first-person and third-person evidence as reported by Smith and Messier (2014) who used fMRI measures associated with verbal reports, could give more support to the evidence that participants are in a different state of consciousness.

\section{Reliability of participants' reports}

In our case, among the possible sources of bias, the chance that the participants' answers simply reflect the hypnotist's knowledge about OBEs must be taken into consideration. It is true that the hypnotist must have an extensive knowledge of the literature related to OBEs, but his aim was not to confirm his knowledge, but to compare it with the participants' experience. In fact, unexpected characteristics of OBEs were discovered (see the companion article by Tressoldi et al. 2015). Furthermore, the questions were designed to be neutral, so as not to suggest or to lead to specific responses.

Other possible sources of bias might be the participants' prior knowledge about OBEs from books or other sources of information like the internet, or what they expect might happen in this particular state of consciousness. This potential source of bias is worthy of consideration. The possibility that all five participants arranged among themselves to give similar answers was excluded, as it would have been necessary for them to access the same books, articles, websites, etc., and it assumes that those sources contained information relevant to all the questions. However, the differences in the percentage of responses with respect to the group of participants who declared only bibliographical and not experiential knowledge and with respect the group of participants who declared at least one spontaneous real OBE, give support to the reliability of true OBEs experienced by our participants.

Another limitation is the lack of practical and reliable instruments to assess the alteration of consciousness when participants declare that they have achieved an OBE state. Unfortunately, at present, there are no such instruments to our knowledge and as a result, different interviews are used in each investigation (e.g., Blanke et al., 2004). 


\section{Future investigations}

Only independent replications of our study can confirm our findings, even though selected participants and experienced hypnotists are required. A more convincing proof of the reality of the $\mathrm{OBE}$ as a distinct disembodied state of consciousness, as documented in our study, could be obtained if we could demonstrate that, when in an OBE state, apart from perception at a distance, it is possible to interact with the physical environment for example "capture" this interaction using electronic devices. This is our research team's next goal. 
Acknowledgments: we thank prof. A. Zane and the Proof Reading Service for English revision.

John Palmer, Athena Demertzi, Charlotte Martial and Aminata Bicego for their review of a previous version of the paper.

We also thank all participants for their commitment in in this study. 


\section{References}

Alvarado, C. S. (1982). ESP during out-of-body experiences: A review of experimental studies. Journal of Parapsychology, 46(3), 209-230.

Blanke, O. (2012). Multisensory brain mechanisms of bodily self-consciousness. Nature Reviews Neuroscience, 13(8), 556-571.

Blanke, O., Landis, T., Spinelli, L., \& Seeck, M. (2004). Out-of-body experience and autoscopy of neurological origin. Brain, 127(2), 243-258.

Blanke, O., \& Arzy, S. (2005). The out-of-body experience: disturbed self-processing at the temporo-parietal junction. The Neuroscientist, 11(1), 16-24.

Blanke, O., \& Castillo, V. (2007). Clinical neuroimaging in epileptic patients with autoscopic hallucinations and out-of-body experiences. Epileptologie, 24, 90 - 96.

Blanke, O., \& Metzinger, T. (2009). Full-body illusions and minimal phenomenal selfhood. Trends in Cognitive Sciences, 13(1), 7 - 13.

Blanke, O., Ortigue, S., Landis, T., \& Seeck, M. (2002). Stimulating illusory own-body perceptions. Nature, 419(6904), $269-270$.

Braithwaite, J. J., Samson, D., Apperly, I., Broglia, E., \& Hulleman, J. (2011). Cognitive correlates of the spontaneous out-of-body experience (OBE) in the psychologically normal population:

Evidence for an increased role of temporal-lobe instability, body-distortion processing, and impairments in own-body transformations. Cortex, 47(7), 839-853.

Cardeña, E. (2005). The phenomenology of deep hypnosis: quiescent and physically active. International Journal of Clinical and Experimental Hypnosis, 53, 37-59.

Cardeña, E. \& Alvarado, C. (2014). Anomalous self and identity experiences. In Cardeña, E., Lynn, S. J. and Krippner, S. (Eds). Varieties of anomalous experience: Examining the scientific evidence. 2nd ed. p.175-212. American Psychological Association.

Carruthers, G. (2013). Who am I in out of body experiences? Implications from OBEs for the explanandum of a theory of self-consciousness. Phenomenology and the Cognitive Sciences, 1-15.

Dan-Glauser, E. S., \& Scherer, K. R. (2011). The Geneva affective picture database (GAPED): a new 730-picture database focusing on valence and normative significance. Behavior Research Methods, 43(2), 468-477.

Gravitz, M. A. (1983). Early uses of the telephone and recordings in hypnosis. American Journal of Clinical Hypnosis, 25(4), 280-282

Ehrsson, H. H. (2007). The experimental induction of out-of-body experiences. Science, 317(5841), 1048-1048.

Ellis, G. F. (2007). Physics in the Real Universe: Time and Space-Time. In Relativity and the Dimensionality of the World (pp. 49-79). Springer Netherlands.

Erickson, M. H. (1952). Deep hypnosis and its induction. In L. M. LeCron (Ed.), Experimental Hypnosis (pp. 70-114). New York: Macmillan. 
Krippendorff, K. (2012). Content analysis: An introduction to its methodology. Sage.

Jourdan, J. P. (2011). Near Death Experiences and the 5th Dimensional Spatio-Temporal Perspective. Journal of Cosmology, 14, 4743-4762.

Metzinger, T. (2005). Out-of-body experiences as the origin of the concept of a 'Soul '. Mind and Matter,3(1), 57 - 84 .

Nash, M. R., Lynn, S. J., \& Stanley, S. M. (1984). The direct hypnotic suggestion of altered mind/body perception. American Journal of Clinical Hypnosis, 27(2), 95-102.

Palmer, J. (1978). ESP and out-of-body experiences: An experimental approach. In D. S. Rogo (Ed.), Mind beyond the body. New York: Penguin Books.

Palmer, J. \& Vassar, C. (1974). ESP and out-of-the-body experiences: An exploratory study. Journal of the American Society for Psychical Research, 68,257-280.

Parnia, S., Spearpoint, K., de, V. G., Fenwick, P., Goldberg, D., Yang, J., ... Schoenfeld, E. R. (2014). AWARE-Awareness during Resuscitation-A prospective study. Resuscitation, 85(12), 1799-1805.

Pascalis, V. D., Russo, P., \& Marucci, F. S. (2000). Italian norms for the Harvard Group Scale of Hypnotic Susceptibility, Form A. International Journal of Clinical and Experimental Hypnosis, 48(1), 44-55.

Petkov, V. (2006). Is there an alternative to the block universe view? in: D. Dieks (Ed.), The Ontology of Spacetime "Philosophy and Foundations of Physics" Elsevier, Amsterdam Series, Volume 1, pp. 207-228. Retrieved from: http://philsci-archive.pitt.edu/9470/

Smith, A. M., \& Messier, C. (2014). Voluntary out-of-body experience: an fMRI study. Frontiers in Human Neuroscience, 8: 70.

Tart, C. T. (1998). Six studies of out-of-body experiences. Journal of Near-Death Studies, 17(2), 73-99.

Terhune, D. B. (2009). The incidence and determinants of visual phenomenology during out-ofbody experiences. Cortex, 45(2), $236-242$.

Tressoldi, P., \& Del Prete, G. (2007). ESP under hypnosis: The role of induction instructions and personality characteristics. Journal of Parapsychology, 71, 125-137.

Tressoldi, P. (2013). OBERecordsImages. figshare. https://dx.doi.org/10.6084/m9.figshare.881821

Tressoldi, P. E., Pederzoli, L., Caini, P., Ferrini, A., Melloni, S., Prati, E., ... \& Trabucco, A. (2015). Hypnotically induced out-of-body experience: How many bodies are there? Unexpected discoveries about the subtle body and psychic body. SAGE Open, 5(4), 2158244015615919.

Wetzels, R., Matzke, D., Lee, M. D., Rouder, J. N., Iverson, G. J., \& Wagenmakers, E.-J. (2011). Statistical evidence in experimental psychology: An empirical comparison using $855 \mathrm{t}$ tests.

Perspectives on Psychological Science, 6, 291-298 


\section{Supplementary Material}

Table S1: Pictures ID and arousal value as reported from the GAPED manual

\begin{tabular}{cc} 
ID & Arousal \\
\hline P050 & 57.6 \\
P097 & 59.5 \\
P105 & 66 \\
P124 & 51.2 \\
H079 & 71.1 \\
H123 & 77.07 \\
\hline
\end{tabular}




\section{STANDARD HYPNOTIC INDUCTION \\ Translated by Cinzia Evangelista Pannozzo, Melbourne, Australia}

\section{INTRODUCTION}

To induce relaxation, a traditionally common technique was used, repeatedly stressing the words relax, muscles, tendons, and ligaments, occasionally mentioning the specific anatomical area on which to focus. The purpose is to distract the subject's attention from normal bodily sensations, which in this situation are considered unwanted background noise, and reach a pre-hypnotic phase based on visualization. This is followed by complete physical relaxation, with the five senses still fully alert to stimuli, and then the typical descending staircase leading to a light at the bottom. An awareness of the escalator is required to avoid boredom and a fear of losing one's balance due to walking down the spiral staircase. Even inside the escalator the senses are alternately stimulated rapidly. When the escalator reaches its destination, hypnotic conditioning is almost complete. A final stage is added in which sensory stimulation continues further, then suddenly stops when the appearance of a cloud-like armchair causes all physical sensation to cease, thus entering the true hypnotic stage. It is important for the guiding voice to remain calm and take part in what is happening.

RELAXATION PHASE (approximately 4 1/2 minutes)

"Begin to relax your toes: start relaxing the muscles and tendons of both big toes, then the next toe, then all the muscles and tendons of the third toe, move to the fourth and then the little toe. Focus on the foot and relax all muscles and tendons of the top of the foot, then those on the sole. Now concentrate on the ankles and relax all those muscles, tendons and ligaments. Move up to the calves and totally relax the muscles, and those of the shin.

Now focus on the knees and relax everything there: muscles, ligaments, tendons... everything inside the knees. Now move your attention to the thighs and let them relax completely, then relax the groin. Move to the gluteal muscles and relax those, then the lower abdominals. Go inside and relax all the intestinal and stomach muscles - let them all go. Focus on the back and relax all muscles and tendons from buttocks to neck.

Now return to the front and relax the remaining abdominal wall muscles, the chest and all the trunk muscles, then focus again on the digestive system: try and stop motion as much as possible, then return to the back and move to the shoulder blades. Relax everything above those: muscles, tendons, everything, and on the front of your body relax everything above the collar bones, especially the neck.

Focus on the shoulder joints and relax them completely: muscles, tendons, ligaments... then move down to the arms and relax likewise there. Totally relax the muscles, tendons and ligaments which join at the elbow. Move down the forearms and focus on relaxing everything there. Now relax the wrists too and their ligaments. Go to the top of your hands and relax all tendons, then the muscles and tendons of the palms.

Now focus on relaxing all the tendons in the thumbs and return to the neck. In the neck, relax all the muscles and tendons in the throat, then those at the back. Move to the muscles in your scalp... relax those also. Relax your forehead, ears, the cheek muscles, the nose, the mouth muscles, and those in the chin.

Now your body is completely relaxed; your heartbeat is slow, each breath is deep, slow, and relaxed, and the blood circulates freely. You are feeling totally at ease and your body has ceased transmitting signals". 
(without interruption) PRE-HYPNOTIC PHASE (approximately $4 \frac{1}{2} 2$ minutes) "Now you are walking barefoot in a meadow surrounded by flowers, you can smell the grass and under your feet you feel the stems with each step, along with the soft earth, which is warm and a little damp. You see many beautiful flowers in many shades of colors: red, blue, orange, purple, yellow, indigo, white. You feel a gentle breeze which carries the scents of all those flowers. With those scents, your mouth can taste their nectar, like diluted honey, a different taste for each flower. You hear birds chirping and insects buzzing, you see wispy clouds in a clear sky, you feel the sun's warmth on your skin... you're totally at ease.

You walk towards a cave-like opening in which you see a balustrade. You approach it and see a very long descending spiral staircase, going deep down into yourself, at the end of which there's a small very bright white light you want to reach.

Beside the balustrade you see an elevator. You walk towards it and press the call button. The doors open and you go inside, pressing the down button. The elevator moves quickly with a light hiss. There's a mirror in front of you, and you see a reflection of yourself as more relaxed and lighter due to the acceleration. You're bathed in a gentle blue light, and in the background, you hear a relaxing music playing at low volume. Under your feet you feel the pleasant roughness of carpet and you lean on the wall, which is a smooth and polished wood.

You catch the smell of freshly baked pastries. Looking around, you see a small triangular table in a corner on which are some pastries. You step towards it, look at them and choose one which appeals to you. As you bring it to your mouth you smell its aroma and then feel its warmth from the oven. You put it in your mouth and savor its delicious taste.

You're very much enjoying this pastry, knowing that when you finish eating, the elevator will have reached its destination inside you. You eat it slowly and as you're almost finished, you feel the elevator decelerating, slowly at first, and then more forcefully. The floor counter appears again and begins the countdown: $-10 .,-9 . .,-8 \ldots,-7 \ldots .,-6 \ldots . .,-5 \ldots \ldots,-4 \ldots \ldots .,-3 \ldots \ldots .,-2 \ldots \ldots \ldots,-1 \ldots \ldots \ldots ., 0$. The elevator stops and the doors open, you exit and find yourself in a room made of rough stone, with a pleasant temperature and humidity, suffused in a green light which casts no shadows; a nice background music is playing and there's an heady fragrance of flowers in the air. There's a black leather armchair in the middle of this room. You go and sit on it, and as you sink into the chair you feel like you're sitting on a cloud. You suddenly feel weightless. It is amazingyou really feel great. You can sense only the leather's slight roughness under your arms and its smell. After a short while those fades away too..."

\section{HYPNOTIC PHASE}

\section{POST-HYPNOTIC PHASE}

"Now rise from the black armchair, go to the elevator and press the call button. The doors open, you enter and press the up button. The doors close and it starts to move with a light hiss. You're perfectly at ease and enjoy the smell of the pastries, the background music and the diffuse blue light as you look at your reflection in the mirror.

The elevator travels very quickly and then begins to rapidly slow down. The floor counter is again visible and begins the countdown: 10., 9.., 8.., 7..., 6...., 5...., 4....., 3......, 2.......,1......., 0 . The elevator stops, the doors open, you exit and are back here again".

\section{USEFUL INFORMATION FOR AN HYPNOTICALLY INDUCED OBE}

In an OBE induced hypnotically the subject is not referred to as a patient, because there is no therapeutic intention or goal; rather, the subject has freely and knowingly volunteered to undergo 
this experience purely for interest and for its potential usefulness. It is therefore more appropriate to refer to the hypnotist as 'Guide' and the person in hypnosis as 'Traveller', given that an OBE is a journey outside the body.

Before beginning the OBE procedure, the Guide and the potential Traveller had better have a detailed discussion to clarify whether there was a genuine desire for knowledge, or simply curiosity. In the latter case it is hardly worth continuing with the OBE because it is extremely likely nothing useful for research purposes will result. A prolonged exchange of ideas will allow a potential Traveller to remove doubts and establish a relationship of mutual trust, therefore facilitating good results. The object is not treatment of any kind but obtaining as much information as possible for both parties, hence the Traveller must be strongly motivated, and not only fearless of hypnosis but have a strong desire for it. All of the above appreciably gets hypnotic induction phase easier. It is important for the Traveller to understand that his/her role is equally as important as the Guide's, although totally different, since the Traveller must be able to answer questions without concerning for their purpose offering the best possible descriptions of what has been seen and felt. The role of the Guide is getting the Traveller, to answer appropriate questions, keeping the Traveller's attention focused and helping overcome any possible difficulties.

During the entire session the Guide must remain fully focused on the Traveller, so as to be aware of any subtle sensations and to impart the feeling of a shared experience without implying direct involvement (the Guide must always remain alert and detached). This is simply non-judgment of what the Traveller says and receiving what is described.

All of this can induce the Guide in an altered state of consciousness so that it gets difficult to carry out even simple arithmetic.

At the conclusion of the OBE session the Traveller, while returning to normal consciousness had better have some time to comment about the more salient points of the OBE itself. In the meantime, an audio recording of the session can be prepared, whose repeated listening can aid the Traveller in remembering more details or removing uncertainties.

\section{TRAINING FOR THE FIRST INDUCED OBE SESSION}

\section{DETACHMENT FROM THE PHYSICAL BODY}

To avoid possible traumas, with related trembling, jolts, and perceived loud noises, a gradual 'exit' from the body is induced at the end of the induction stage using the following guidelines: "You are now gently moving out of your body, slowly and without haste, until you find yourself completely outside of it. You don't feel any discomfort, but actually you feel better once outside." Wait for few seconds in silence, then: "Now that you're 'outside' your physical body, you only need to express the intention to move or travel and you will do so immediately. Try to turn around and then go up towards the ceiling and look down at your body below."

\section{MOVING THROUGH WALLS}

The next step must be executed immediately, without waiting for replies and before the physical body begins to pull the 'outside entity' back into itself and consists of making the non-physical entity move through walls and/or ceilings. Depending on the experiment location, you choose the most suitable wall surface and then give the following instructions: "Now move towards that wall/ceiling, lean on it and note that you can go through it as if it were a projected image rather than a real object. Express the intention of moving through it and you'll find yourself immediately on the other side." 


\section{CONTROL OF SPEECH}

At this point it is important to establish two-way communication with what we have defined the 'outside entity'. We have found the following instructions to be optimal: "Now that you're outside the room, find a peaceful place, stop and be fully aware of being outside your body; concentrate on your physical body for the time needed to allow it to talk. When you've done this, say 'yes'.'

\section{FLIGHT AND TRAVEL TECHNIQUES}

Upon receiving the confirmatory 'yes', two-way communication has now been acquired. It is cautious, however, not to linger there, because focusing on the physical body results in a loss of control of the 'outside entity' and in this early stage of training it is best to avoid distractions. We choose a location known to both parties and we commence (first travel procedure): "Now go to (place name). Move around purely through intention. Go slowly at first, then gradually move faster, following the road you're familiar with. While travelling, practice full control of motion. When you arrive at the destination, say 'yes'."

For the return trip another technique is used (second travel procedure): "Now return to your point of departure in a straight line and as fast as possible, ignoring roads. When you get there, say 'yes'." The third technique is done at infinite speed (instantaneously). The instruction is: "Think of the train station and try to get there immediately. When you're there, say 'yes'. Did you get there instantly or not?"

\section{THE TRAIN'S DEPARTURE}

If the answer is 'yes', the train station has been reached, and therefore:

"Find a train about to leave, go in front of it, then enter it, either standing on the tracks or floating above them. Wait until the train departs the station and get it to move along you. Look inside it as it moves past and note that you feel nothing."

\section{TIME AND DATE}

Since the 'outside entity' is at a train station, we can ask it to read the time and date; the answer is usually inconsistent with the actual time, which can be either in the past or in the future (normally by no more than a few months). When asked if it is night or day, the answer usually matches the perceived time, but when asked if the sun is shining and if shadows are seen, the answer is usually this: "There's a diffuse light, which casts no shadows." Even people, who usually crowd a train station, are very often not seen at all, or just perceived as 'lots of shadows. After this experience, we check that the 'outside entity' has no problems placing itself in the middle of a road while cars are passing by, without fear of injury.

At this point basic training has finished; questions can be asked, and answers received, delayed at first and eventually with greater speed. It must be remembered however that in order to speak, the 'outside entity' must always focus on the physical body, thus reducing its level of attention even when speaking get easier. If more complex answers are required, it is suggested to give the 'outside entity' time to concentrate on the answer, as in the following instruction: "Look at (or listen to) such and such, take your time to concentrate on it to the exclusion of anything else, then answer only when you're sure of your answer."

NB: the best results are obtained when the Traveller has had time (at least half an hour) to relax sight and hearing before undergoing the OBE. A pleasant journey is ideal. 